\title{
Cartografía del paisaje audiovisual a comienzos del siglo XXI. Disney, un imperio mediático global
} Cartography of the audiovisual landscape at the beginning of the 21st century. Disney, a global media empire

Miguel Ángel Rivas Romero

${ }^{1}$ Departamento Historia del Arte, Universidad de Málaga, España (mabusla@ hotmail.com)

RESUMEN: Este trabajo tiene como objetivo el estudio de la problemática de época que ha causado la transformación del cine al hipercine y sus implicaciones: el paso de la pantalla única a la pantalla global, la muerte del cine, la relación de este arte con la transformación hipermoderna, conflictos entre la cinefilia y la cinemanía así como la necesidad de una metodología de análisis global. Después profundizamos en el hipercine dentro del contexto de esta segunda modernidad, desde cómo le ha afectado el proceso de tecnificación que sufre la sociedad, pasando por un análisis del cine actual como arte inmerso en una espiral cuyo centro es el marketing, para finalizar estudiando al hiperespectador y los procesos constitutivos del hipercine. Centrándonos en The Walt Disney Company como paradigma del modelo empresarial mediático hipermoderno, cuyo liderazgo se basa en el sinergismo intermedial y en la creación de narrativas transmedia, por sus distintas confluencias en relación con el mundo de la cultura y elarte.

PALABRAS CLAVE: Disney, Lucasfilm, Pixar, Marvel, Cine, Cultura visual.

\begin{abstract}
The main objective of this study is to analyse the changes that has taken the cinema to be transformed into hypercinema. We have attended to a transformation of the exclusive screen to the global screen, to a metaphorical death of cinema, taking part into the transformation process of hypermodernity, not even leaving alone the concepts of cinephilia and/or ciemania and arising the need of a new methodology that framework such approach. The concept of "hypercine" is born into the second modernity and it has affected the process of technification that society has overcome. We are going to take over an analysis of contemporary cinema as a form of art immersed in a spiral of marketing strategy predominantly ending with the study of the "hyperspectator" and the core idea as a base for "hypercine". As a real witness of this theory we are going to use The Walt Disney Company because it offers us the point of view of "hypermodern" media enterprise, due to its style
\end{abstract}


of leadership based on intermedial synergism as well as the creation of "transmedia storytelling" into the framework of cultural atmosphere and arts ${ }^{e e}$ world.

KEYWORDS: Disney, Lucasfilm, Pixar, Marvel, Cinema, Visual Culture.

\section{Introducción}

El núcleo del sistema, alrededor del cual orbitan las diversas tipologías que configuran las producciones audiovisuales de comienzos del nuevo milenio, cuya existencia se sustenta en la luz indirecta que de este reciben, no es ni mucho menos un sol moribundo, como anuncian numerosos profetas apocalípticos, creyentes de un tiempo pasado idealizado e inexistente. Estos terrores milenaristas surgen de la incapacidad de algunos de percibir que estamos inmersos en un cambio de era audiovisual y, como en anteriores crisis -pues no es esta la primera- el choque de placas tectónicas está provocando unas transformaciones profundas e irreversibles del paisaje audiovisual, haciendo que las anteriores edades queden reflejadas en estratos, como sedimentos testimoniales permeables. La transformación profunda y radical que la cartografía del paisaje audiovisual viene experimentando desde comienzos del siglo XXI, y su influencia sincrónica en todos los medios, en todas las esferas de nuestra sociedad y, como no podría ser de otro modo, en todas las artes y en determinados artistas, es el objeto de estudio de este artículo.

\section{Cartografía del paisaje audiovisual a comienzos del siglo XXI}

El cine, arte e industria del entretenimiento, nació unido, en perpetua simbiosis armónica, con un espacio mágico y figurativo donde proyectar nuestros sueños y pesadillas, donde nuestros deseos más íntimos conviven con miedos ancestrales; un espejo de fantasmas que refleja lo que somos, lo que queremos ser, lo que seremos; una superficie que compone, dispone y predispone; un lugar donde las imágenes conforman un cielo donde algunas estrellas brillan, eternas, mientras otras son fugaces sueños de una noche de verano. Gracias a la gran pantalla, que nunca fue solo un apéndice técnico, el cine ha sido el arte del siglo XX, el arte de nuestro tiempo. Pero en la década de los 50 la tela blanca conoció a su hermana pequeña: la televisión. En las siguientes décadas fue reclamando su lugar predominante en los principales avances tecnológicos, de los ordenadores de sobremesa a los portátiles, de las videoconsolas a los teléfonos móviles. Gracias a su alianza con Internet, aquel trozo de tela ha pasado de ser una pantalla-espectáculo a una pantalla-comunicación, de la unipantalla a 
la omnipantalla". "Es la era de la pantalla global. [...] el nuevo siglo es el siglo de la pantalla omnipresente y multiforme, planetaria y multimediática" (Lipovetsky, Serroy, 2009:10).

El triunfo de la "pantalla esfera", aunque ha transformado nuestra forma de vernos a nosotros mismos y de ver el mundo, no ha podido con un arte que, gracias a su inconcreta identidad, fundamentada sobre el dinamismo propio de su modernidad, ha sido capaz de redefinirse en un proceso de mutación cultural sin precedentes. A pesar de las transformaciones que el medio ha sufrido, en su producción, difusión y consumo, o de la creciente competencia de otros modos de entretenimiento, el cine está afrontando el desafío apostando por la diversidad y aumentando el número de estrenos.

Aunque las películas dotadas de mayor presupuesto son las más taquilleras, los estudios han sabido detectar la existencia de un nuevo espectador interesado en películas más modestas, pero que narran historias singulares, con frecuencia de temática comprometida (Lipovetsky, 2002: 33-46). Aunque estas obras alcanzan el éxito sin estrellas, esto no quiere decir que vivamos el fin del star system $^{2}$. Así, en respuesta a una sociedad cada vez más parcelada, el cine produce tanto superproducciones para un público mundial homogéneo, como películas pequeñas, no en el sentido artístico, para unos espectadores heterogéneos, pues es en ellas donde todos las edades, identidades, géneros y culturas son dignas de ser representadas. Pero a pesar de que el medio haya perdido su centralidad, su influencia cultural global se manifiesta en la visión cinematográfica con la que el individuo moderno mira el mundo. No vivimos la muerte del cine sino su nueva mutación.

\section{La transformación hipermoderna}

Según Lipovestsky y Serroy mientras que determinados momentos anteriores cimentaron y edificaron la modernidad del cine, con esta última fase se supera. Así, el medio vuelve a redefinirse, pasando del cine al hipercine, comenzando la historia hipermoderna del séptimo arte. El cambio de paradigma que Lipovetsky denomina hipermodernidad "se caracteriza por afectar en un movimiento sincrónico y global a las tecnologías y los medios, a la economía y a la cultura, al consumo y a la estética. El cine sigue la misma dinámica. Precisamente cuando se consolidan el hipercapitalismo, el hipermedio y el hiperconsumo globalizados, el cine inicia su andadura como pantalla global"

\footnotetext{
${ }^{1}$ La mayoría de los términos no admitidos por la RAE utilizados en este trabajo han sido acuñados por Lipovetsky. ${ }^{2}$ La presencia de ciertos nombres en una película, con independencia de sus capacidades artísticas, atrae la atención del público y son, casi siempre, sinónimo de éxito. Si analizamos la lista de los y las mejores pagados del 2016 vemos algunos nombres vinculados a grandes éxitos de taquilla, pero también a sonoros fracasos como es el caso de Johnny Depp con Alicia a través del espejo (James Bobin, 2016) o Scarlett Johansson con la reciente adaptación del anime Ghost in the Shell (Rupert Sanders, 2017).
} 
(Lipovetsky, Serroy, 2009: 22). La "pantalla global" remite a la pantallaesfera, al mundo pantalla erigido sobre Internet, y a las pantallas de carácter lúdico, informativo, de vigilancia o simplemente de ambientes en lugares de tránsito. Conformando, una pantallocracia que engloba al arte digital, el videoclip, el videojuego, la publicidad, la fotografía digital, nuestra forma de comunicarnos con el mundo y con nuestros semejantes, nuestra vida, e incluso la creación, el acceso y la distribución del conocimiento.

En la era de la globalización económica, la deslocalización de los centros de producción ${ }^{3}$ y de la internacionalización de las inversiones financieras, Hollywood está bajo el control de grupos japoneses, chinos ${ }^{4}$ y europeos. Así mismo, como más de la mitad de los ingresos de las películas producidas por los grandes estudios americanos se generan fuera de sus fronteras, este cine global ha tenido que incorporar a su fórmula cada vez más ingredientes multiculturales: asimilando, por necesidad, nuevas sensibilidades y temas; abriéndose a nuevos modelos, a nuevos relatos, donde no se excluyen las diversas experiencias e identidades.

\section{El hipercine}

La sociedad global está inmersa en una segunda modernidad (dejando desfasada la modernidad modernista anterior), a la que Lipovetsky denomina "[...] hipermoderna y que se expresa tanto en los signos de la cultura como en la organización material del hipermundo [...]” y que se manifiesta "[...] a través de una triple metamorfosis que se refiere al orden democrático-individualista, a la dinámica de mercado y a la tecno-ciencia” (Lipovetsky, Serroy, 2009: 48-49). En nuestra sociedad hipermoderna, caídos los muros levantados por las fuerzas opositoras a la modernidad, todo se expande sin control, triunfando el exceso. Esta segunda modernidad cabalga a lomos de un caballo desbocado que emprende una huida hacia adelante sin destino concreto. El cine actual participa de esta ultramodernidad con sus imágenes y argumentos, con la incorporación desmesurada de los continuos avances tecnológicos.

\footnotetext{
${ }^{3}$ Países como Canadá se han convertido en los lugares donde se ruedan gran parte de los estrenos de la cartelera, pero también la mayoría de las series de televisión. Este país gracias a una política de ventajas fiscales ha conseguido atraer a la industria audiovisual mundial.

${ }^{4}$ Wanda Group, líder mundial del sector de bienes inmuebles, es un conglomerado chino multinacional propietario de la mayor cadena de cines del mundo, Wanda Cinemas, y de la española Cinesa. En nuestro país su presencia tiene una fuerte influencia en el cine y en el deporte, pues son propietarios del 20\% del Atlético de Madrid. Wanda ha comprado el estudio americano Legendary Entertaiment por 3.500 millones y está construyendo el mayor complejo cinematográfico del mundo, Movie Metrópolis, en la ciudad china de Quingdao.
} 


\section{La hipertecnificación}

La historia del cine siempre ha sido la de un arte que navega siguiendo el curso marcado por el desarrollo de nuevas tecnologías. En las cuatro últimas décadas asistimos a un auténtico vendaval de inventos tecnológicos que han transformado la producción, la distribución y la exhibición de las películas.

El espectador de la década de los 80 que veía las películas en casa en dispositivos de video doméstico con una calidad de imagen y sonido inferior a las salas de cine, en los 90 disfrutaría del formato DVD con una imagen y sonido digital de alta calidad. Después llegaría Internet, los nuevos formatos como el Blu-ray, el 4K, las pantallas domésticas cada vez más grandes y más planas, los ordenadores portátiles, las tablets y los teléfonos móviles, con sus pantallas pequeñas pero cada vez con mayor calidad de video y de sonido ${ }^{5}$. Pero esta revolución digital no afecta solo a la estética de la recepción y a la distribución de contenidos, sino también a los procesos de producción fílmicos. Las cámaras digitales han hecho posible que las etapas en las que se dividían la concepción de las películas se hayan fusionado. La tecnología digital permite insertar a los actores en decorados inexistentes o solo parcialmente construidos, en mundos pertenecientes a nuestro pasado o imaginarios, creados por concept artist. Como escribió el filósofo Baudrillard, las producciones digitales matan la realidad sin dejar huellas, en un sentido indicial, de certificado de autenticidad, como sí hacía la imagen fotoquímica, según Roland Barthes. La revolución y el éxito de las series, que se están produciendo para los canales de televisión o plataformas de VOD (Netflix, HBO, etc.), sería imposible sin el impulso de las técnicas digitales.

Nos encontramos con un cine donde lo visual y el efecto se imponen sobre el argumento, en un hipercine de atracciones donde el espectador se sumerge en un torbellino de formas, colores y sonidos a un ritmo acelerado. El espectador actual, miembro de la denominada me generation, quiere que el cine, compuesto por imágenes sensoriales donde prima el exceso, le haga experimentar sensaciones de gran intensidad que satisfagan su apetito insaciable, la adicción del individualismo moderno a la velocidad, a la inmediatez, a la moda como conjunción de lo efímero y de la fantasía estética (Lipovetsky, 2000: 37), a tenerlo todo, "I want it all, and I want it now"6.

\footnotetext{
${ }^{5}$ Las actuales salas de cine dotadas con proyectores digitales y sus sistemas de sonido inmersivo no solo exhiben películas en 2D, 3D o UHD, en español o en V.S.O. sino también eventos deportivos en directo, conciertos de música, ballet, ópera, etc.

${ }^{6}$ La mítica banda de rock inglesa Queen anticipaba en su canción I Want it All, perteneciente al álbum The Miracle (1989), cantaba a modo de himno profético la frase que mejor define al individuo actual.
} 


\section{El imperio del marketing}

Los productores actuales piensan que para reducir riegos hay que realizar películas cada vez más caras, con presupuestos de más de 200 millones de dólares, para que los espectadores acudan a las salas atraídos por la promesa de asistir a un acontecimiento sin precedentes. El aumento de la inversión en las superproducciones supone una reducción en las películas más “pequeñas”. En el cine, como espejo de nuestra sociedad digital que se asienta sobre un sistema binario, de pocos unos y de muchos ceros, también aumenta la distancia entre ricos y pobres. Las estrellas de cine suelen coquetear, firmando lucrativos contratos, con el mundo de la moda, con la Alta Costura, y la publicidad, tan influenciados por el cine y viceversa. La moda definida por lo efímero, la seducción y la diferenciación marginal (Lipovetsky, 2000: 175), y la publicidad, tecnología de los desplazamientos del deseo (Lipovetsky, 2000: 224), se aprovechan del star system cinematográfico y, al mismo tiempo, lo retroalimentan. La moda, las estrellas y la publicidad son construcciones artificiales de seducción (Lipovetsky, 2000: 243), pues “consumimos como espectáculo lo que la vida real nos niega” (Lipovetsky, 2000: 251). El hipercapitalismo lleva en su código genético el gen de la desigualdad, pero también el de la estetización del mundo (Lipovetsky, Serroy, 2015).

Para minimizar el riesgo comercial de un mega-acontecimiento mediático supone destinar hasta la mitad del presupuesto de la producción a las campañas publicitarias. Esta saturación presupuestaria y promocional se traduce en una concentración del éxito y del fracaso. Por ello, el cine norteamericano actual se sustenta sobre un sistema de explotación de franquicias, cuyo retorno económico sigue la siguiente jerarquía: el merchandising ${ }^{7}$ (Gubern, 2013: 398); el mercado doméstico; la explotación en las plataformas televisivas, VOD, etc., por último, las salas de cine.

\section{El hiperconsumidor}

La posibilidad de disfrutar de producciones audiovisuales en todo tipo de dispositivos domésticos o portátiles, incluidos los teléfonos móviles, en cualquier lugar y momento, se adapta mejor a la vida de los consumidores, "porque el individuo actual desea ser autónomo y construye libremente, a la carta, su entorno personal" (Lipovetsky, 2002: 28). Si el espectador de cine iba a las salas para soñar con otras vidas; el hiperconsumidor, quizás influenciado por la realidad virtual, la industria del videojuego, quiere sentir, ser sorprendido, experimentar, vivir en vez de soñar. 


\section{El cine, un arte hipermoderno}

El hipercine no solo supone un cambio en su vertiente industrial, sino que afecta también al propio lenguaje cinematográfico, a su estilo, a la construcción de las imágenes, a su gramática. Este cine ultramoderno se caracteriza por tres clases de imagen (Lipovetsky, Serroy, 2009: 68-69), en cuyo código genético portan una lógica "híper”:

1.- La imagen-exceso, efecto directo de la informática y la digitalización, caracterizada por una estética del "nunca es demasiado", por la lógica del exceso. Más velocidad, más ritmo, más sexo, más violencia estetizada, más efectos, más planos, tomas más cortas, más metraje, más volumen, más persecuciones, más montaje nervioso, más diálogos breves, más bombardeo sonoro y visual, más sensaciones, más inmersión, más emoción, más vértigo, más, más y más. El cine hipermoderno huye de lo cotidiano, de los tiempos muertos, le aterra lo poco ${ }^{8}$; alejándose de cualquier proporción, orden y medida, del justo medio aristotélico, ofreciendo al espectador todo tipo de perversiones sexuales ${ }^{9}$ y violencia extrema.

2.- La imagen-multiplejidad. A pesar de que las superproducciones de éxito de Hollywood siguen usando una fórmula renovada de su estética narrativa clásica, el cine actual se caracteriza por una predilección por lo multiforme, lo híbrido y lo plural. Nunca se había cuidado tanto la preparación de una película, ni jamás se había profundizado con tanto empeño en la búsqueda de las diversas formas de narrar una historia, ni en la ambigüedad del sentido ${ }^{10}$.

3.- La autorreferencia constante que conduce a la imagen-distancia. Aunque el cine siempre se ha citado a sí mismo, en el hipercine este ejercicio se incorpora como parte de su lenguaje, no como homenaje, ejercicio formal o referencialidad reflexiva con valor de reivindicación crítica y de autoría. El arte del cine genera una cultura propia y se alimenta de ella con fines diversos ${ }^{11}$.

Quedando liberado de normas, de regulaciones estéticas y morales, el cine experimenta un proceso similar "al que condujo de los medios a los hipermedios, del capitalismo al hipercapitalismo, del

\footnotetext{
${ }^{8}$ Mad Max: Furia en la carretera (George Miller, 2015) es puro exceso, una oda a la velocidad ininterrumpida.

${ }^{9}$ Un buen ejemplo de este cine es la espléndida Elle (Paul Verhoeven, 2016).

${ }^{10}$ Sirvan estos ejemplos: Animales nocturnos (Tom Ford, 2016), La Llegada (Denis Villeneuve, 2017) o Paterson (Jim Jarmusch, 2016).

${ }^{11}$ Se produce entonces una paradoja: mientras se reduce la distancia entre el espectador y la imagen mediante la inmersión sensorial, mediante el uso de las citas, aumenta la distancia, pero en un sentido intelectual, las imágenes invitan al espectador a un juego de ingenio y complicidad. Esta dualidad, aparentemente contradictoria, permite que el espectador se encuentre tanto fuera como dentro de las películas. El musical La Ciudad de las Estrellas. La La Land (Justin Hurwitz, 2016), es una cita desde el principio hasta el final.
} 
consumo al hiperconsumo" (Lipovetsky, Serroy, 2009: 70). Este hipercine no se construye en oposición antagónica a ningún modelo pretérito. Ya no se distinguen los límites, porque han dejado de existir, entre industria y arte, entre cine comercial y de autor. La hipercultura que está gestándose durante estas dos primeras décadas que llevamos de siglo XXI, se construye sobre creación y fórmula, sobre calidad y mediocridad, sobre high art y low art.

\section{Disney, un imperio mediático global basado en el sinergismo intermedial}

Para evitar la pérdida del liderazgo indiscutible que ostentaba desde 1930, al menos en el mundo de la animación tradicional, The Walt Disney Company decidió retomar un modelo de negocio basado en el sinergismo intermedial diseñado por Walt Disney en 1957 (Zenger, 2013) [1]. Una teoría corporativa de crecimiento sostenible capaz de posicionar a la empresa como el principal conglomerado mediático de comunicación y entretenimiento mundial de comienzos del siglo XXI. Esta estrategia establece que la película es el activo central que aporta valor a otra serie de activos (cómics, parques temáticos, revistas, música, etc.) relacionados con el entretenimiento, que a su vez infunden valor añadido a las producciones cinematográficas. Esta estrategia no solo se basa en reconocer las sinergias de los activos propios sino buscar la adquisición de otros.

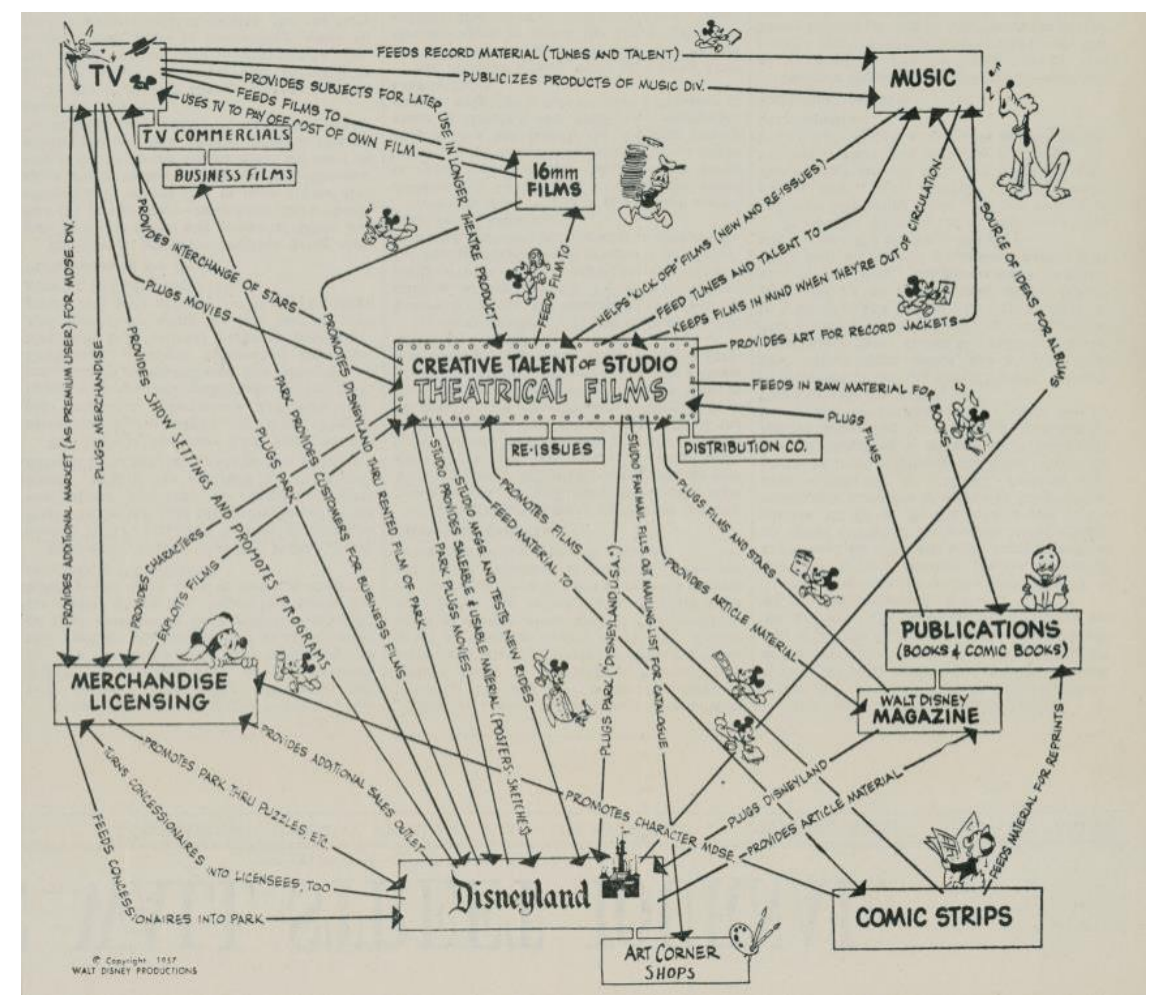

1. Esquema empresarial diseñado por Walt Disney. Fuente: @ 1957 Disney 
Así, Disney ha conseguido el liderazgo en taquilla durante los años 2016 y 2017 [2], gracias a su productora cinematográfica, Walt Disney Pictures ${ }^{12}$; a su estudio de animación, Walt Disney Animation Studios ${ }^{13}$, productor de Frozen (Chris Buck, Jennifer Lee, 2013) ${ }^{14}$; sumándose las nuevas adquisiciones: Pixar Animation Studios ${ }^{15}$ en 2006, Marvel Studios ${ }^{16}$ en 2009 y Lucasfilm ${ }^{17}$ en 2012 [3]. Todas estas nuevas compañías adquiridas siempre han mantenido una estrecha relación con Disney; siendo la fusión de todas ellas una mera cuestión de necesidad, oportunidad y tiempo.

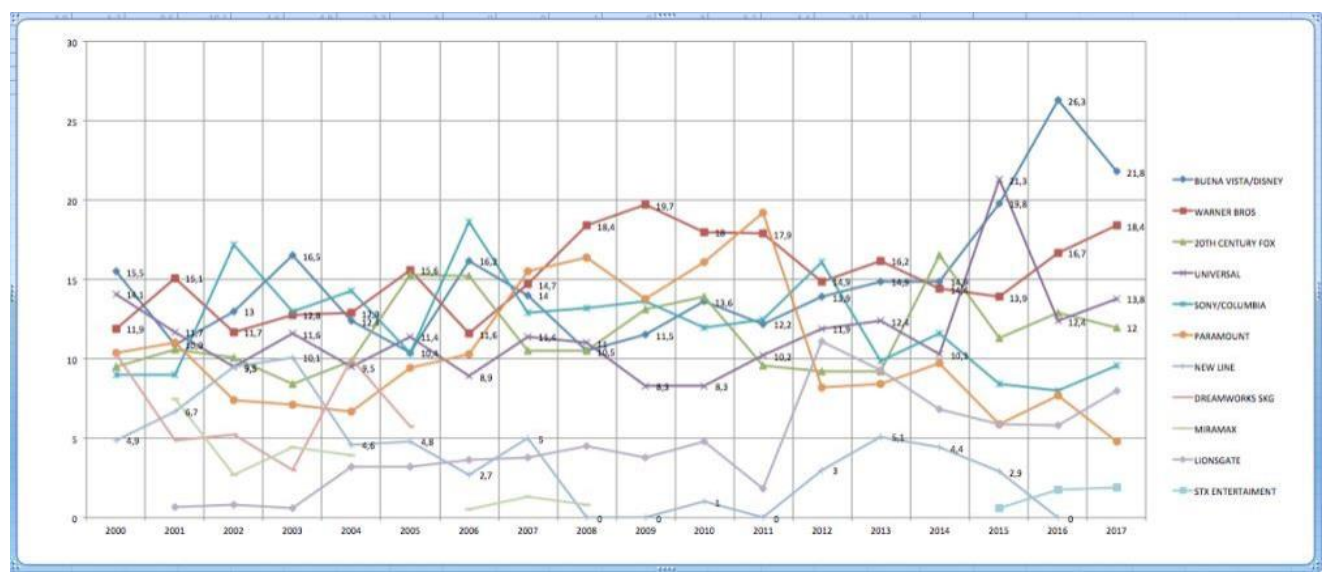

2. Cuotas de mercado de la taquilla por estudio. Fuente: http://boxofficemojo.com

\begin{abstract}
${ }^{12}$ Walt Disney Pictures es la encargada de las franquicias como Piratas del Caribe o de las adaptaciones de clásicos animados como Maléfica (Robert Stromberg, 2014), Cenicienta (Kenneth Branagh, 2015), El libro de la selva (Jon Favreau, 2016) o La Bella y la Bestia (Bill Condon, 2017). Alan Horn, el directivo que despidió Warner, ha conseguido reflotar la división cinematográfica de Disney. Sus nuevas adaptaciones a imagen real, han sido todo un éxito económico, logrando conectar a dos generaciones de espectadores, y permitiendo que la compañía renueve sus propiedades intelectuales.

${ }^{13}$ No debemos caer en el error de vincular todas las producciones animadas de Disney a su filial Pixar. Walt Disney Animation Studios, su estudio de animación para cine y televisión ha producido 56 películas, desde Blancanieves y los siete enanitos (1937) hasta Moana (Ron Clements, John Musker2016), y no son pocos los críticos que manifiestan que en estos últimos años la calidad artística de las películas producidas por el estudio está siendo superior a las de Pixar.

${ }^{14}$ Una película cuya trama está muy influenciada por el tratamiento que Marvel le dio a su universo X-Men. La editorial siempre ha usado los cómics de los mutantes como metáfora para tratar temas relacionados con la exclusión y el rechazo que sufren las minorías. La protagonista de Frozen, al igual que los superhéroes, nace con una serie de poderes que la hacen distinta a los demás. La película es un canto a la aceptación de las diferencias por parte de la sociedad, de nuestra familia, pero, sobre todo, de nosotros mismos.

${ }^{15}$ División informática de Lucasfilm creada en 1979 y dirigida por el doctor Edwin Catmull, incorporando en 1984 a John Lasseter, animador formado en Disney. Ambos crearían el primer personaje totalmente digital para una película: $E l$ Caballero de la Vidriera para el film El secreto de la pirámide (Barry Levinson, 1985). La empresa fue adquirida en 1986 por Steve Jobs. La relación con Disney comenzó con el acuerdo alcanzado con para los efectos de La Sirenita (Ron Clement, John Musker, 1989), Los rescatadores en Cangurolandia (Hendel Butoy, Mike Gabriel, 1990) y la escena del baile de La Bella y la Bestia (Gary Trousdale, Kirk Wise, 1991). En 1991 firmaron el acuerdo para la realización de 3 largometrajes. Después del éxito de Toy Story (John Lasseter, 1995), en 1997 se firmó un nuevo acuerdo para seguir produciendo largometrajes pero repartiendo los beneficios a partes iguales. Durante estos años, las producciones de Pixar para Disney encadenaron un éxito tras otro tanto de crítica como de público.

${ }^{16}$ Tras el éxito de X-Men (Brian Synger, 2000) para la Fox y de Spiderman (Sam Raimi, 2002) para Sony, Marvel anunció en 2005 que comenzaría a producir películas de forma independiente. A partir del éxito de su primera producción, Iron Man (Jon Favreau, 2008), la empresa viene desarrollando una estrategia muy rentable, que consiste en estrenar sus películas en distintas fases. El "arquitecto" y alma máter del Marvel Cinematic Universe (MCU) es Kevin Feige. La presentación de las producciones que se van a estrenar en la fase siguiente se realizan siguiendo el modelo que canonizó Steve Jobs para Apple.

${ }^{17}$ En junio de 2012, Kathleen Kennedy, colaboradora en las películas de Indiana Jones y productora de E.T. (Steven Spielberg, 1982), la trilogía Regreso al futuro o Parque Jurásico, es nombrada co-presidenta de Lucasfilm. Kennedy se convierte en la depositaria del legado de George Lucas, en la persona encargada de forjar un nuevo futuro para la empresa.
\end{abstract}




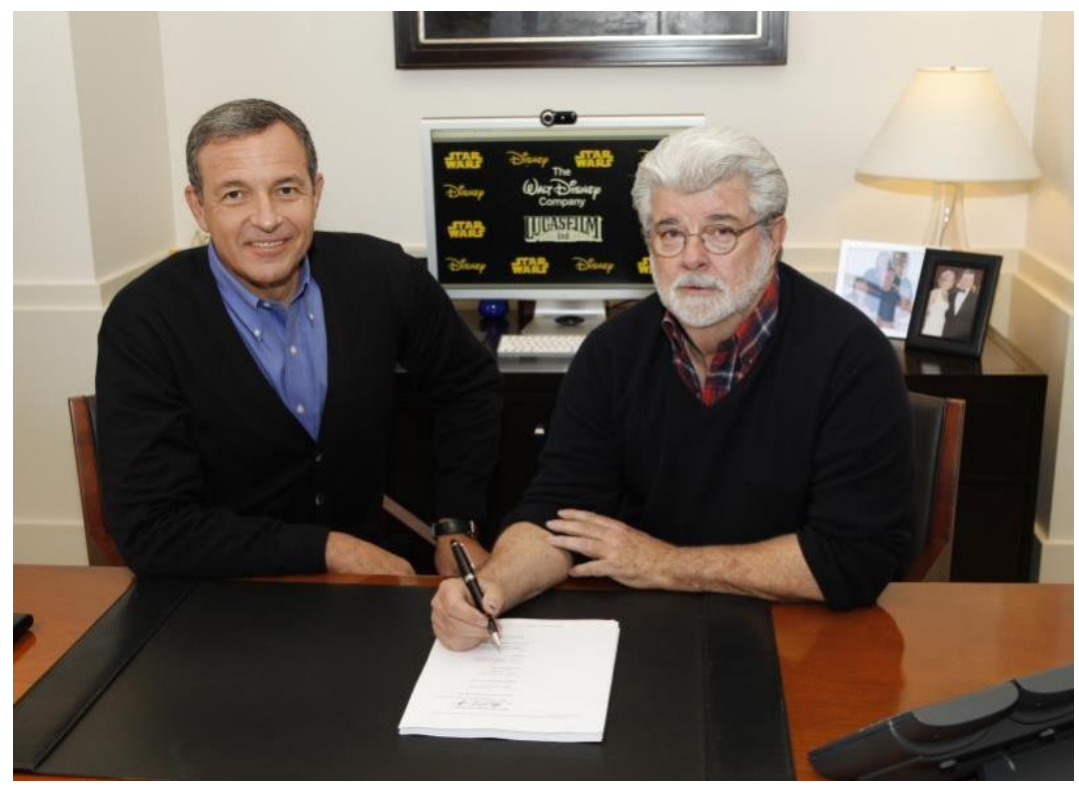

3. George Lucas firmando la venta de Lucasfilm a Disney. Fuente: Disney/ABC Television Group

Todas las empresas incorporadas mantienen su independencia creativa, pero contando con el apoyo mediático y económico de Disney: sus parques temáticos, sus canales de televisión y su compañía discográfica, sus tiendas, etc.

\section{Disney y el mundo de la cultura}

Disney no es solo el estudio con más seguidores del mundo, sino también el más atacado por la élite cultural internacional y por numerosos colectivos de la sociedad. En un mundo binario, los artistas con respecto a Disney se posicionan bien en el bando de los apocalípticos, como Banksy con su Dismaland (2015), bien en el de los integrados, como Dalí, Warhol, y los integrantes del empresarialismo: desde Damien Hirst pasando por Murakami hasta Jeff Koons.

\section{Artistas apocalípticos}

Disneyland París, que este año celebra su 25 aniversario, y es la atracción turística más visitada de Europa, solo ha tenido beneficios en 5 ocasiones. Es un proyecto que se construyó sobre una previsión de costes incorrecta y que no tuvo en consideración ciertos aspectos culturales. Antes de su inauguración, los intelectuales franceses manifestaron que el parque era un atentado contra el modo de vida europeo, un "Chernóbil cultural”. Sus inversores esperan que la incorporación de las atracciones basadas en Star Wars, supongan el impulso que el parque necesita para salir de los 
números rojos, pues cerrarlo no es una opción porque supondría un coste muy alto para la reputación de Disney, mayor incluso que las pérdidas anuales.

A estas voces críticas contra Disney se han sumado las propuestas de numerosos artistas. La más relevante desde el punto de vista artístico y mediático fue el proyecto Dismaland $(2015)^{18}$ ideado por Banksy, el artista más importante del street art británico, cuya traducción al castellano sería algo como "Tierra Deprimente". Este parque de atracciones o macroinstalación, "lectura distópica [...] de Disneylandia, traducida en una inversión ontológica del concepto de parque de atracciones" (Moriente, 2015: 47), contaba con todas las instalaciones, atracciones y servicios típicos de este tipo de lugares, pero sometidos a una relectura: el desasosiego y la depresión. El evento Dismaland fue una propuesta figurativa y narrativa, una reflexión satírica, tragicómica y paródica, con un marcado carácter político, de nuestro mundo dominado por los medios de masas, la publicidad y las marcas; una metáfora del fracaso de la cultura del simulacro y de la modernidad.

\section{Artistas integrados}

Mientras que algunos artistas han utilizado a la empresa o a sus iconos como reflexión sobre los problemas del mundo, otros han optado por una visión más amable, contribuyendo así a una legitimación del legado artístico de Walt Disney libre de prejuicios. Además, estos artistas crean su obra y su fortuna con una estrategia empresarial que fascinaría al propio Disney, llevando al límite el concepto warholiano de factoría, pues no dudan en crear conglomerados empresariales para satisfacer un mercado que demanda sus producciones.

En 1954, Walt Disney y Salvador Dalí colaboraron en la producción de Destino, un corto animado que quedó inacabado. En 1999, el sobrino de Walt Disney, Roy E. Disney, mientras trabajaba en Fantasía 2000 (1999), retomó el proyecto. Destino (Dominique Monféry, 2003) fue nominado a los Oscar en 2003 como mejor corto de animación y exhibido en varios festivales internacionales.

En la obra del artista pop Andy Warhol (1928-1987, Nueva York) podemos encontrar un recorrido por los mitos más importantes del siglo XX, desde Marilyn Monroe hasta Elvis. En su serie Myths (1981) incluyó una obra cuyo protagonista era Mickey Mouse.

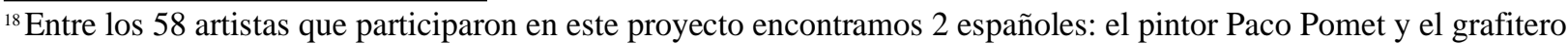
valenciano Escif.
} 
Para Damien Hirst, "Mickey Mouse representa la felicidad y alegría de ser un niño. He querido simplificar su forma a los elementos más básicos, unos simples lunares o puntos. Espero que a la gente le guste porque es algo que se reconoce instantáneamente. Mickey es sin duda un icono universal y muy poderoso". Así hablaba de su obra Mickey (2012) subastada a favor de la organización solidaria Kids Company en Christie's. La obra del artista de Bristol se ha encontrado en varias ocasiones con Disney, pues en su más reciente aventura en Venecia, entre las múltiples esculturas que conforman la muestra titulada Tesoros del naufragio del "Increíble" (2017), que profundiza en los límites del arte como posverdad, entre las 200 obras que componen la muestra, encontramos dos esculturas de Mickey Mouse, una de la mano de su creador y otra en solitario, y un Goofy. Vemos que algunos artistas como el de Bristol, quien también expuso una obra en el Dismaland de Banksy, se posiciona en ambos "bandos", demostrando que en la hipermodernidad los dos polos no son excluyentes. Bienvenidos a la hipermodernidad, a un mundo de paradojas.

\section{Conclusiones}

Aunque el cine actual ha perdido la posición dominante que tuvo durante todo el siglo XX, en la cultura hipermoderna, su espíritu, marcado por el culto a lo visual y al star system, sigue vivo. Sus principales competidores (Internet, los videojuegos, la televisión y los espectáculos deportivos), al mismo tiempo que devoran sus cuotas de mercado y se apropian de sus espectadores/consumidores, se impregnan de la esencia de la estética cinematográfica. El espíritu del cine subyace oculto en el núcleo motriz del resto de producciones audiovisuales, como un generador expresivo que, gracias a las pantallas móviles, desde la epidermis del medio se proyecta al espectador, poseyéndolos, apropiándose de sus gustos, maneras y comportamientos, de su privacidad, de su vida.

El espectador se ha convertido en director y actor, en sujeto y objeto, de la película de su vida: el cinenarcisismo del individuo en perpetua colisión con la de sus semejantes. La huida hacia adelante del cine, en la época de la todopantalla, para alcanzar una cinevisión globalizada, ha difundido la mirada del cine y multiplicado la vida de la imagen en movimiento, creando una cinemanía planetaria: el culto del individuo contemporáneo a lo hipervisual, cuya matriz es el espíritu del cine que recorre el mundo, que fluye por las arterias de la Red, saltando de pantalla en pantalla.

El cine, en el ocaso de su preeminencia pretérita, se alza como un educador de una mirada cinematográfica global, que penetra en todos los estratos de la sociedad. La vida y el mundo vistos 
por el individuo contemporáneo como si fuesen cine. La vida no solo imita al Arte, sino que la vida es vista a través del Arte.

The Walt Disney Company se erige como paradigma del modelo empresarial mediático hipermoderno, cuyo liderazgo dentro de la industria del cine, durante los años 2016 y 2017, se basa en la explotación de franquicias mediante el sinergismo intermedial y la creación de narrativas transmedia. Solo las empresas que asimilan el modelo de gestión Disney son capaces de seguir en los primeros puestos (Warner Bros., 20th Century Fox y Universal).

El ámbito de la cultura y todos sus agentes, con independencia de su posicionamiento, no pueden mantenerse ajenos al impacto del mayor productor de imágenes de la actualidad. Armados con el aparato crítico propio de las humanidades debemos aceptar el desafío. Porque este ratón tiene hambre.

\section{Referencias bibliográficas}

BISKIND, Peter (2008). Moteros tranquilos, toros salvajes. La generación que cambió Hollywood. Anagrama: Barcelona.

CAPODAGLI, Bill, JACKSON, Lynn (2008). La gestión al estilo Disney, Deusto: Barcelona. FANNING, Jim (2016). El libro de Disney. DK: Londres.

FINCH, Christopher (2011). El arte de Walt Disney: De Mickey Mouse a Toy Story. Lunwerg: Barcelona.

GARCÍA GÓMEZ, Francisco, PAVÉS, Gonzalo (2014). Ciudades de cine. Cátedra: Madrid.

GUBERN, Román (2013). Cultura audiovisual. Escritos 1981-2011. Cátedra: Madrid.

HOWE, Sean (2013). Marvel Comics. La historia jamás contada. Panini: Gerona.

JULLIER, Laurent, (2006). ¿Qué es una buena película? Paidós: Barcelona.

KUSHINS, Josh (2017). Star Wars El arte de Rogue One. Planeta Cómic: Barcelona.

LIPOVETSKY, Gilles (2000). El imperio de lo efímero. Anagrama: Barcelona.

LIPOVETSKY, Gilles (2002). Metamorfosis de la cultura liberal. Anagrama: Barcelona.

LIPOVETSKY, Gilles, SERROY, Jean (2015). La estetización del mundo. Anagrama: Barcelona. 
LIPOVETSKY, Gilles, SERROY, Jean (2009). La pantalla global. Anagrama: Barcelona.

LONGWORTH, Karina (2012). Masters of Cinema: George Lucas. Phaidon: New York.

MORIENTE, David (2015). "De vándalo a artista: Banksy”, Anuario del Departamento de Historia y Teoría del Arte, Barcelona, Universitat Internacional de Catalunya, vol. 27, pp. 31-52.

PAIK, Karen (2007). To Infinity and Beyond. The Story of Pixar Animation Studios. Virgin Books Ltd: London.

SANDERSON, Peter (2013). Marvel crónica visual definitiva, Londres, DK: Londres.

SCOLARI, Carlos (2013). Narrativas transmedia. Cuando todos los medios cuentan. Deusto: Barcelona.

SZOSTAK, Phil (2015). El arte de Star Wars. El despertar de la Fuerza. Planeta Cómic: Barcelona.

ZENGER, Todd (2013). “The Disney Recipe”. Harvard Business Review. Recuperado de www.hbr.org/2013/05/what-makes-a-good-corporate-st (Consultado 02/12/2016). 